"This is the peer reviewed version of the following article: Foot of the Wave Analysis for Mechanistic Elucidation and Benchmarking Applications in Molecular Water Oxidation Catalysis ,which has been published in final form at http://onlinelibrary.wiley.com/doi/10.1002/cssc.201601286/abstract

This article may be used for non-commercial purposes in accordance with Wiley Terms and Conditions for SelfArchiving."

\title{
Foot of the Wave Analysis for Mechanistic Elucidation and Benchmarking Applications in Molecular Water Oxidation Catalysis
}

\author{
Roc Matheu, ${ }^{[\mathrm{a}],[\mathrm{b}]}$ Sven Neudeck, ${ }^{[\mathrm{c}]}$ Franc Meyer, ${ }^{[\mathrm{c}],[\mathrm{d}]}$ Xavier Sala $^{*[\mathrm{e}]}$ and Antoni Llobet ${ }^{*,[\mathrm{e}],[\mathrm{e}]}$
}

Abstract: The description of the foot of the wave analysis (FOWA) applied to the electrocatalytic oxidation of water to dioxygen is reported for cases where the rate determining step is first order and second order with regard to catalyst concentration. This coincides with the so called water nucleophilic attack (WNA) and interaction of two M-O units (I2M) mechanism respectively. The newly adapted equations are applied to a range of relevant molecular catalysts both in homogeneous and heterogeneous phase and the kinetic parameters, including apparent rate constants and turnover frequencies, are determined. In this respect the application of FOWA at different catalyst concentrations allows elucidating the reaction mechanism that operates in each case. In addition catalytic Tafel plots are used for assessing the performance of several molecular water oxidation catalysts (WOCs) as a function of overpotential under analogous conditions and thus can be used for benchmarking purposes. While this had been earlier carried out for oxide based WOCs, now it is the first time reported for molecular WOCs.

\section{Introduction}

Hydrogen generated by water splitting with sunlight is today considered as one of the most promising energy vectors for replacing fossil fuels. ${ }^{1,2,3}$ This can be achieved using

[a] Pr. A, Llobet and Mr. R, Matheu

Institute of Chemical Research of Catalonia (ICIQ), Barcelona

Institute of Science and Technology

Avinguda Països Catalans 16, 43007 Tarragona, Spain

[b] Mr. R, Matheu

Departament de Química Física i Inorgànica

Universitat Rovira i Virgili

Marcel-lí i Domingo s/n, 43007 Tarragona, Spain

[c] Pr. F, Meyer and Dr. S, Neudeck

Institute of Inorganic Chemistry

Georg-August-University Göttingen, D-37077 Göttingen, Germany

[d] Pr. F, Meyer

International Center for Advanced Studies of Energy Conversion

Georg-August-University, 37077, Göttingen, Germany

[e] Pr. A, Llobet and Dr. X, Sala

Departament de Química

Universitat Autònoma de Barcelona, Cerdanyola del Vallès, 08193

Spain.

allobet@iciq.cat and xavier.sala@uab.cat

Supporting information for this article is given via a link at the end of the document. photoelectrochemical cells where water oxidation is occurring at the anode and proton reduction at the cathode, driven by sunlight. ${ }^{4}$ The $\mathrm{H}_{2}$ obtained in this way is generally termed solar fuel, generated by an artificial photosynthetic device, in analogy with the main mode of action of photosynthesis in green plants and algae. ${ }^{5}$ The anodic water oxidation reaction is one of the key reactions involved in these processes common to both water splitting with sunlight and natural photosynthesis, and thus it is essential for the construction of functional devices ${ }^{6,7}$ as well as for the comprehension of the reactions involved in natural photosynthesis. ${ }^{8}$ In addition, the water oxidation anodic reaction can be potentially coupled to other interesting reactions such as $\mathrm{CO}_{2}$ or $\mathrm{N}_{2}$ reduction reactions to build artificial photosynthetic devices for instance for the generation of $\mathrm{MeOH}$ or $\mathrm{NH}_{3}$ respectively. ${ }^{9,10,11}$ The water oxidation reaction thus emerges as the key partner for various reduction reactions for energy and industrially relevant applications in the near future. For this reason it is imperative to understand the main pathways involved in the catalytic water oxidation reaction as well as the pathways that deactivate the catalyst. ${ }^{12,13,14}$ In this respect water oxidation catalyzed by molecular transition metal complexes represent an ideal ground because of the ligand engineering possibilities for modulating the electronic and steric properties of the catalyst. ${ }^{15}$

While the capacity of transition metal oxides to carry out water oxidation to dioxygen has been known for a long time ${ }^{16,17,18,19}$ and recently benchmarked, ${ }^{20,21,22}$ that of molecular transition metal complexes is more recent and has boomed only over the last 10 years. ${ }^{12,23,24,25,26,27,28,29,30}$ There is nowadays a variety of transition metal complexes that have been reported to very efficiently oxidize water to dioxygen. However the conditions under which the catalysis is carried out differ from one another and hamper a meaningful comparison. In addition precise electrochemical methods are not available when S-shape catalytic response is not obtained. ${ }^{31,32,33,34}$

Thus there is a need to develop techniques to benchmark water oxidation catalysis with molecular systems in order to be able to identify the best catalyst for a given application. For this purpose we have adapted the so called "Foot of the Wave Analysis" (FOWA) for water oxidation catalysts that can be applied even when an ideal S-shape response is not obtained in Cyclic Voltammetry. The methodology is based on the analysis of the first points of the catalysis, where the catalytic response is 
unperturbed by side phenomena that usually prevents the extraction of the kinetic information. The methodology was first reported by Costentin, Robert, Saveant et al. ${ }^{35}$ and was applied to the electrocatalytic reduction of protons and carbon dioxide. ${ }^{36,37,38,3940,41}$ Recently, Mayer et al. ${ }^{42}$ have also shown a very nice agreement between apparent rate constants derived spectroscopically by UV-vis and based on FOWA for the catalytic oxygen reduction, which further validates this methodology.

Herein we extend the concept of FOWA to catalytic water oxidation by molecular transition metal complexes. We thus report the FOWA mathematical equations adapted for electrocatalytic water oxidation reactions and their applications to some of the most relevant examples reported so far in the literature. ${ }^{43,44,45,46,47}$ Chart 1 shows drawn structures and general nomenclature of the water oxidation catalysts discussed in the present work. In addition, the FOWA methodology is used as a tool for the elucidation of reaction mechanisms for these molecular water oxidation catalysts (WOCs), in particular with respect to the O-O bond formation. Finally, based on the FOWA results catalytic Tafel plots are reported for all these WOCs under similar conditions, allowing for a fair comparison among them.

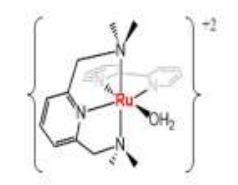

$\left[\text { Ru' }(\text { damp })(\text { bpy })\left(\mathrm{H}_{2} \mathrm{O}\right)\right]^{2+}$ $1^{2+}$

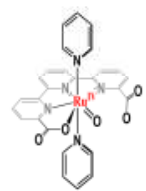

$\left[\operatorname{Ru}^{\prime I V}(\mathrm{O})(\mathrm{tda})(\mathrm{py})_{2}\right]$ 4

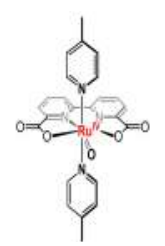

$\left[\mathrm{Ru}^{\mathrm{IV}}(\mathrm{O})(\mathrm{bda})(4-\mathrm{Me}-\mathrm{py})_{2}\right]$

2

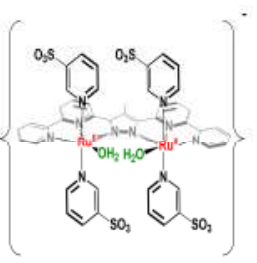

$\left\{\left[\mathrm{Ru}^{\prime \prime}\left(\mathrm{OH}_{2}\right)\left(4-\mathrm{SO}_{3}-\mathrm{py}\right)_{2}\right]_{2}(\mu-\mathrm{Mebbp})\right\}$

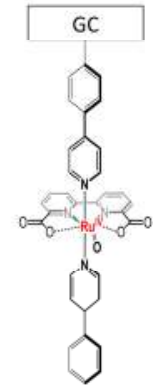

GC-2
Chart 1. Drawn structure of the complexes discussed in this work.

\section{Results}

2.1 Main mechanistic scenarios described for molecular water oxidation catalysts

Scheme 1 shows the reaction mechanism proposed for complex $\left[R u^{\prime \prime}\left(\right.\right.$ damp) $\left(\text { bpy) }\left(\mathrm{H}_{2} \mathrm{O}\right)\right]^{2+}, \quad \mathbf{1}^{2+} \quad$ (damp is 2,6bis(dimethylaminomethyl)-pyridine and bpy is 2,2'-bipyridine; see Chart 1$)^{43}$ and the seven coordinated complex $\left[\mathrm{Ru}^{\mathrm{IV}}(\mathrm{O})(\mathrm{bda})(4-\mathrm{Me}-\mathrm{py})_{2}\right], 2\left(\mathrm{pKa}\left(\mathrm{Ru}^{\mathrm{IV}}-\mathrm{OH} / \mathrm{Ru}^{\mathrm{IV}}-\mathrm{O}\right)=5.9 ; \mathrm{bda}^{2-}\right.$ is 2,2'-bipyridine-6,6'-dicarboxylate and py is pyridine). ${ }^{45}$ These two complexes follow two different $\mathrm{O}-\mathrm{O}$ bond formation pathways that are representative of the main mechanisms that have been reported in recent years ${ }^{25,48,49,50}$ For the sake of simplicity and easy follow up of electron counting, we will refer only to formal oxidation states at the Ru metal center. This does not neglect the obvious total or partial contribution from the Ru bonded terminal oxido or hydroxido ligands on the removal of electron density especially at high oxidation states. Complex $\mathbf{1}^{2+}$ follows the so-called water nucleophilic attack (WNA) mechanism where the $\mathrm{O}-\mathrm{O}$ bond formation occurs via a nucleophilic attack of solvent water to an electrophilic $\mathrm{Ru}^{\mathrm{V}}-\mathrm{O}$ group and is the rate determining step (rds), as is also proposed for a number of so called single site catalysts. ${ }^{51}$ The rate constants for the WNA step and the last ET step are also indicated in Scheme 1 and presented as equations 1 and 2 below,

$\left[(\text { damp })(\text { bpy }) \mathrm{Ru}^{\mathrm{IV}}-\mathrm{O}\right]^{2+}-1 \mathrm{e}-->\left[(\text { damp })(\mathrm{bpy}) \mathrm{Ru}^{\mathrm{V}}-\mathrm{O}\right]^{3+}$

$\left[(\text { damp })(\text { bpy }) \mathrm{Ru}^{v}-\mathrm{O}\right]^{3+}+\mathrm{H}_{2} \mathrm{O} \rightarrow\left[(\text { damp })(\text { bpy }) \mathrm{Ru}^{\prime \prime \prime}-\mathrm{OOH}\right]^{2+}+\mathrm{H}^{+}$

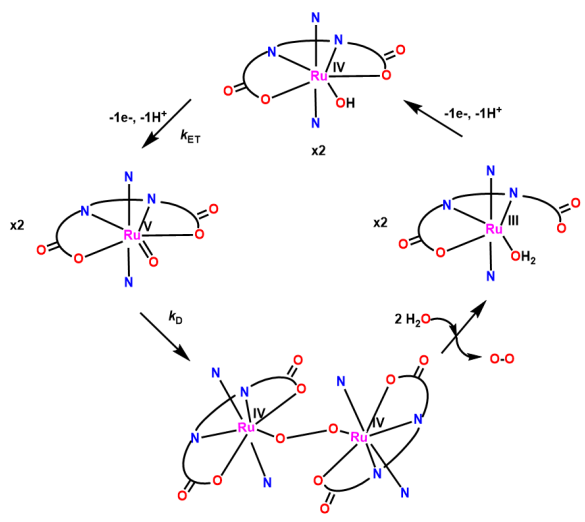


Scheme 1. Main O-O bond formation mechanism described for molecular water oxidation catalysis. Top, WNA mechanism proposed for $\left[R u^{\prime \prime}\left(\text { damp)(bpy) }\left(\mathrm{H}_{2} \mathrm{O}\right)\right]^{2+}, \mathbf{1}^{2+}\right.$. The $3 \mathrm{~N}$ and $2 \mathrm{~N}$ linked by arcs represents the damp and bpy ligands respectively. Bottom, I2M mechanism proposed for $\left[\mathrm{Ru}^{\mathrm{IV}}(\mathrm{O})(\mathrm{bda})(4-\mathrm{Me}-\mathrm{py})_{2}\right], 2$. The $\mathrm{O}$ and $\mathrm{N}$ linked by arcs represent the bda ${ }^{2-}$ ligand whereas the picoline ligand is represented by a single $\mathrm{N}$.

On the other hand the Ru-bda complex $2 \mathrm{H}^{+}$, at low $\mathrm{pH}$, follows the so-called interaction of two $\mathrm{M}-\mathrm{O}$ units (I2M) mechanism where the $\mathrm{O}-\mathrm{O}$ bond formation is proposed to occur via dimerization of two $\mathrm{M}-\mathrm{O}$ groups. ${ }^{45}$ For a mononuclear complex this is an intermolecular reaction but for a dinuclear complex this

$$
\begin{gathered}
{\left[(\text { bda })(\text { py })_{2} \mathrm{Ru}^{\mathrm{IV}}-\mathrm{OO}-\mathrm{Ru}^{\mathrm{IV}}(\mathrm{bda})(\mathrm{py})_{2}\right]^{2+}} \\
+2\left[(\mathrm{bda})(\mathrm{py})_{2} \mathrm{Ru}^{2 \mathrm{II \prime}}\left(\mathrm{OH}_{2}\right)\right]^{+}+\mathrm{O}_{2}
\end{gathered}
$$

$\left[(\mathrm{bda})(\mathrm{py})_{2} \mathrm{Ru}^{\mathrm{IV}}-\mathrm{OO}-\mathrm{Ru}^{\mathrm{IV}}(\mathrm{bda})(\mathrm{py})_{2}\right]^{2+} \quad-1$ e-

$$
\left[(\text { bda })(\text { py })_{2} \mathrm{Ru}^{\mathrm{IV}}-\mathrm{OO}-\mathrm{Ru}^{\mathrm{lV}}(\mathrm{bda})(\mathrm{py})_{2}\right]^{3+}
$$

$\left[(\text { bda })(\text { py })_{2} \mathrm{Ru}^{\mathrm{IV}}-\mathrm{OO}-\mathrm{Ru}^{\mathrm{IV}}(\mathrm{bda})(\mathrm{py})_{2}\right]^{3+}+2 \mathrm{H}_{2} \mathrm{O}$

\begin{tabular}{|c|c|c|c|c|c|}
\hline WNA & & I2M & & Hetero-WNA & \\
\hline $\begin{array}{c}\mathrm{P} \rightarrow \mathrm{Q}+\mathrm{e}^{-} \\
\mathrm{Q}+\mathrm{H}_{2} \mathrm{O} \stackrel{k_{4}}{\rightarrow} \mathrm{P}+\mathrm{O}_{2}\left(k_{1} \cdot\left[\mathrm{H}_{2} \mathrm{O}\right]=k_{W N A}\right)\end{array}$ & (5) & $\begin{array}{l}\mathrm{P} \rightarrow \mathrm{Q}+\mathrm{Q}^{-} \\
\mathrm{Q}+\mathrm{Q} \rightarrow 2 \mathrm{P}\end{array}$ & (6) & $\begin{array}{c}\text { het }-\mathrm{P} \rightarrow \text { het }-\mathrm{Q}+\mathrm{e}^{-} \\
\text {het }-\mathrm{Q}+\mathrm{H}_{2} \mathrm{O} \stackrel{k_{1}}{\rightarrow} \text { het }-\mathrm{P}+\mathrm{O}_{2}\end{array}$ & (7) \\
\hline$\frac{i}{E_{p}}=\frac{4 \cdot 2.24 \sqrt{\frac{R \cdot T}{F \cdot v} \cdot k_{W N A}}}{1+e\left(\frac{F\left(E^{0}-E\right)}{R T}\right)}$ & (8) & $\frac{i}{i p}=\frac{4 \cdot 2.24 \cdot \sqrt{\frac{R \cdot T}{3 \cdot F \cdot v} \cdot k_{D} \cdot C_{\text {Cat }}^{0}}}{\left(1+e\left(\frac{F\left(E^{0}-E\right)}{R T}\right)\right)^{\mathrm{a} / 2}}$ & (9) & $\frac{i}{Q_{R u}}=\frac{k_{W N A}}{1+e\left(\frac{F\left(E^{0}-E\right)}{R T}\right)}$ & (10) \\
\hline $\mathrm{TOF}=\frac{k_{W N A}}{1+\mathrm{e}\left(\frac{F\left(E^{0}-E_{H_{2} O / O_{z}}-\eta\right)}{R T}\right)}$ & $(11)$ & $\mathrm{F}=\frac{\frac{1}{3} \cdot k_{D} \cdot C_{C \sigma \varepsilon}^{0}}{\left(1+e\left(\frac{F\left(E^{0}-E_{K_{2} O / O_{z}}-\eta\right)}{R T}\right)\right)^{3 / 2}}$ & (12) & $\mathrm{TOF}=\frac{k_{\text {WNA }}}{1+e\left(\frac{F\left(E^{0}-E_{H_{2} O / O_{2}}-\eta\right)}{R T}\right)}$ & (13) \\
\hline $\mathrm{TOF}_{\mathrm{MAX}}=k_{W N A}$ & (14) & $\mathrm{TOF}_{\mathrm{MAX}}=1 / 3 \cdot k_{D} \cdot C_{\text {Cat }}^{0}$ & (15) & $\mathrm{TOF}_{\mathrm{MAX}}=k_{W N A}$ & $(16)$ \\
\hline
\end{tabular}

Table 1. Summary of reactions and key equations obtained for the WNA, I2M and hetero-WNA mechanisms including TOF- $\eta$ relationships and TOF formulas.

Abbreviations used: $C^{0}$ or or $[R u]$, initial bulk concentration of catalyst; $E^{\circ}$, standard potential for the $\mathrm{P}$ and $\mathrm{Q}$ Couple; $E_{\mathrm{H} 2 \mathrm{O} / \mathrm{O} 2}$, standard potential of oxidation of water at the working $\mathrm{pH} ; F$, Faradaic constant; $\eta$, overpotential; $i$, CV current intensity; $i_{p}$, peak current intensity of one-electron redox process of the catalyst; $k_{1}$, apparent WNA rate constant; $k_{\mathrm{WNA}}$, apparent WNA pseudo-rate constant $\left(k_{1} \cdot\left[\mathrm{H}_{2} \mathrm{O}\right]\right) ; k_{\mathrm{D}}$, apparent dimerization constant; $Q_{R u}$, moles of electrons associated with a 1 electron transfer process of the immobilized catalyst; $R$, gas constant; $T$, temperature; TOF, turn over frequency; $x$, distance from the electrode surface. could potentially occur in an intramolecular manner. ${ }^{52}$ In the former case the dimerization is produced upon reaching the $\mathrm{Ru}(\mathrm{V})$ state and under stoichiometric conditions the slowest steps are associated with the dimerization process $\left(k_{D}=1.1 \mathrm{x}\right.$ $\left.10^{5} \mathrm{M}^{-1} \mathrm{~s}^{-1}\right)$ and the subsequent oxygen ejection $\left(k_{\mathrm{O} 2}=5.8 \mathrm{~s}^{-1}\right)$ displayed in equations $3 a$ and $3 b$ respectively and in Scheme 1. In both cases the kinetic processes are independent of the [Ce(IV)] used as chemical oxidant. Given the second and first order nature of $k_{D}$ and $k_{\mathrm{O} 2}$ respectively, the rds of the process depends on the initial concentration of Ru. For low [Ru] (below the $5 \mu \mathrm{M}$ range) the dimerization process $(3 \mathrm{~b})$ is the rds and above the $0.5 \mathrm{mM}$ range the oxygen ejection $(3 \mathrm{c})$ is the rds. Further under excess of $\mathrm{Ce}$ (IV) the peroxo is proposed to be further oxidized to superoxo (4a) that in turn evolves oxygen (4b) Both processes are described to be very fast under these conditions and thus the kinetics again are independent of [Ce(IV)] and the rds is governed by $k_{D}$ at the $\mathrm{Ru} \mu \mathrm{M}$ concentration range.

\subsection{The FOWA equations for water oxidation catalysis.}

We have adapted the FOWA methodology $y^{35-39}$ using the equations 5 and 6 (see Table 1) for the WNA and I2M mechanisms respectively in homogeneous phase. Therefore, we used the generic "P" and " $Q$ " labels that correspond to equations 1-2 and 3a-3b respectively just described above for catalyst $1^{2+}$ and 2. In both cases, we are assuming that the O-O bond formation is the rds. Other scenarios for water oxidation catalysis with different rds steps are not considered in the present work; however systems where the rds is first order with regard to $[\mathrm{Ru}]$ will also be comprised within the equations of the WNA mechanisms ${ }^{49}$ as will be the intramolecular $\mathrm{O}-\mathrm{O}$ bond formation in dinuclear complexes. ${ }^{47,53,54}$

$2\left[(\text { bda })(p y)_{2} R^{\mathrm{V}}-\mathrm{O}\right]^{+}--------->\left[(\mathrm{bda})(\mathrm{py})_{2} \mathrm{Ru}^{\mathrm{IV}}-\mathrm{OO}-\mathrm{Ru}^{\mathrm{IV}}(\mathrm{bda})(\mathrm{py})_{2}\right]^{2+}$ 


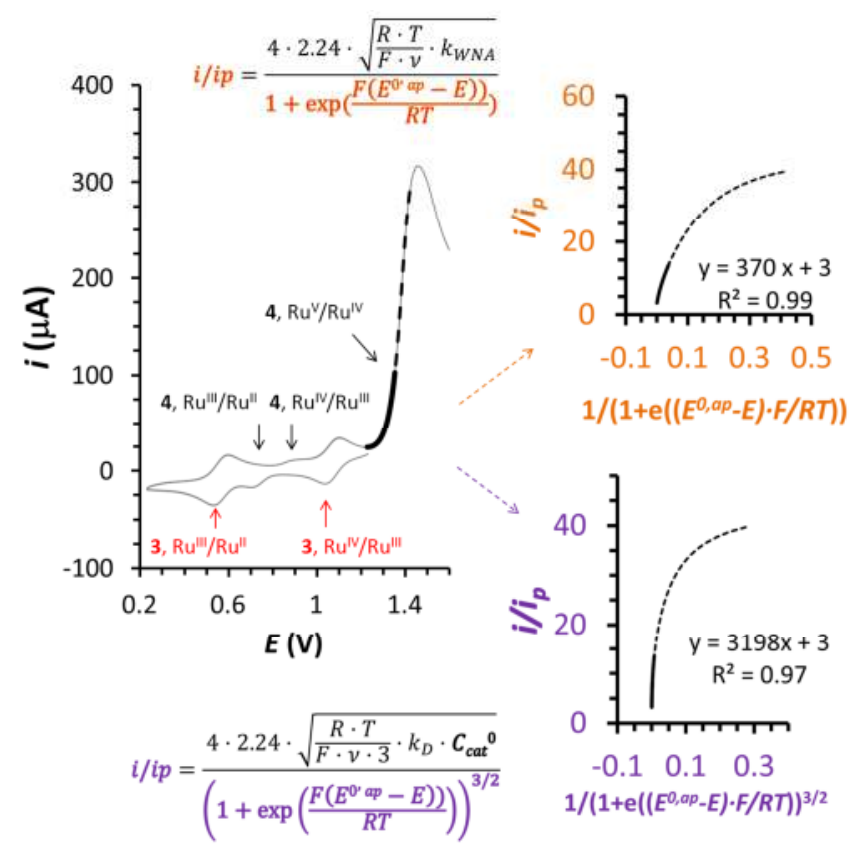

Saveant. ${ }^{55}$ Within this framework it is important to realize that the key features that distinguish the FOWA equations for the WNA vs. I2M mechanisms are the different dependences of " $i / i_{p}$ " on catalyst concentration (where " $i$ ", is the current intensity at the $\mathrm{CV}$ and " $i_{p}$ " is the peak current intensity of the one electron redox process of the catalyst; see equations 8 and 9 in Table 1). This concentration dependence is an intrinsic property of each mechanism that will be used for the subsequent discussions. Further the turnover frequency (TOF) and its maximum value, TOF $_{\text {MAX, }}$ are two key features for the proper catalyst characterization, whose equations (11-14) are displayed in Table 1 for both the WNA and I2M mechanisms.

We also have applied the FOWA formalisms to GC-2, which is a homologue of catalyst 2 attached to the surface of an electrode, under severely restricted translational mobility conditions, and thus with basically no diffusion. We have used the chemical equations 7 (Table 1) with the generic terminology "het-P" and "het-Q", to denote the heterogeneous phase nature for the anchored catalyst, under different oxidation states and deduced its corresponding TOF and TOF $\mathrm{MAX}$ equations 13 and 16.

Table 2. Kinetic, thermodynamic data and experimental conditions for the complexes studied in the present work.

\begin{tabular}{|c|c|c|c|c|c|c|c|}
\hline Complex & $p H$ & $\begin{array}{c}\text { Mec. FOWA } \\
(\text { Mec. Lit })^{b}\end{array}$ & $\begin{array}{c}\text { TOF } \\
s^{-1}\end{array}$ & $T O F_{E_{C e}}{ }^{c}(T O F \text { lit })^{d}$ & $\begin{array}{l}k_{D} \cdot 10^{-3} \\
s^{-1} M^{-1}\end{array}$ & $E^{o, a p} V^{e}$ & $\begin{array}{c}{[R u]^{f}} \\
m M\end{array}$ \\
\hline 4 & 7.0 & WNA & $(7.7 \pm 1.5) \cdot 10^{3}$ & 0.37 & --- & 1.43 & $0.15-1.5$ \\
\hline $5^{-}$ & 1.0 & WNA $(\text { WNA })^{g}$ & $50 \pm 10$ & $0.07(0.07)^{\mathrm{h}}$ & --- & 1.71 & $0.08-0.79$ \\
\hline 2 & 1.0 & I2M (I2M) $)^{i^{\prime}}$ & $11 \pm 3^{j}$ & $11^{\mathrm{j}}(30)^{\mathrm{k}^{\prime}}$ & $170 \pm 50$ & 1.39 & 0.2 \\
\hline 2 & 7.0 & $\mathrm{I} 2 \mathrm{M}$ & $11 \pm 3^{j}$ & 11 & $160 \pm 30$ & 1.08 & $0.12-0.84$ \\
\hline 2 & 12.0 & $\mathrm{I} 2 \mathrm{M}$ & $11 \pm 3^{j}$ & 11 & $170 \pm 40$ & 1.08 & $0.14-0.94$ \\
\hline GC-2 & 7.0 & WNA & $1.9^{l}$ & $1.9^{\prime}$ & --- & 1.08 & $0.05-0.4^{m}$ \\
\hline
\end{tabular}

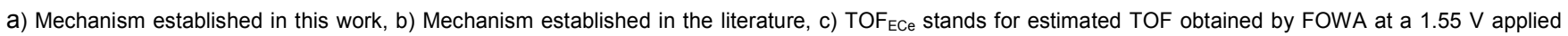
potential; that is the $\mathrm{Ce}(\mathrm{IV}) / \mathrm{Ce}(\mathrm{III})$ standard potential calculated with the FOWA equations based on the kinetics obtained for complex 5 using Ce(IV) as oxidant, under the conditions used here. See text for more information and reference 67, d) Calculated TOF using Ce(IV) as a sacrificial oxidant in the literature, e) Apparent potential of the redox couple extracted from DPV in this work, f) Concentration range used in this work, g) The mechanism was elucidated based on isotope labeling experiments, ${ }^{47} \mathrm{~h}$ ) Experimental conditions: $\left[\mathrm{CF}_{3} \mathrm{SO}_{3} \mathrm{H}\right]=0.1 \mathrm{M},\left[\mathrm{Ce}\left(\mathrm{NH}_{4}\right)_{2}\left(\mathrm{NO}_{3}\right)_{6}\right]=0.1 \mathrm{M}$ and $\left.[\mathrm{Ru}]=1 \mathrm{mM},{ }^{47} \mathrm{i}\right) \mathrm{Mechanism}$ stablished thought

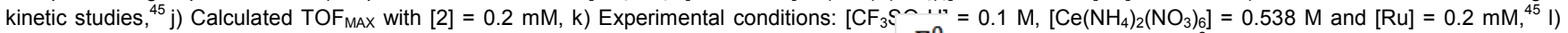
Calculated from the average of CVs from GC-2 electrodes at low superficial concentration $\left(\Gamma_{c c}^{0}=0.10\right.$ and $\left.0.06 \mathrm{nmol} / \mathrm{cm}^{2}\right)$, m) Superficial concentration range $\left(\mathrm{nmol} / \mathrm{cm}^{2}\right)$.

Figure 1: Left, grey solid line shows a CV of a $3 / 4$ mixture $(3.0 \mathrm{mM} / 1.5 \mathrm{mM})$ at $\mathrm{pH}=7.0$. The black dashed line indicates the data points used for the FOWA. The black solid arrows indicate the one-electron processes of complexes 3 and $4{ }^{44}$ Top right, $i / i_{p}$ vs. $\left[1 /\left(1+\mathrm{e}\left(\left(E^{o, a p}-E\right)(F / R T)\right)\right)\right]$ plot assuming a WNA mechanism and the used equation. Bottom right, $i / i_{p}$ vs. $\left[1 /\left(1+\mathrm{e}\left(\left(E^{o, a p}\right.\right.\right.\right.$ $E)(F / R T)))^{3 / 2}$ ] plot assuming an I2M mechanism and its equation. The fitting points for the extraction of rate constants at the foot of the wave are represented as a black solid line in the three graphs.

A complete mathematical description of the FOWA equations is presented in the $\mathrm{SI}$ and the most relevant are gathered at Table 1. It is worth mentioning that for the WNA mechanism, $k_{W N A}$ is an apparent pseudo-rate constant defined as $k_{W N A}=k_{1} \cdot\left[\mathrm{H}_{2} \mathrm{O}\right]$ (see Table 1) that is associated with the chemical reaction (equation 2) following electron transfer. In a similar manner $k_{D}$ correspond to the dimerization process (equation $3 \mathrm{~b}$ ) that occurs after electron transfer in the I2M mechanism. A related bimolecular mechanism had been previously considered by Costentin and
2.3 The FOWA methodology applied to $\left[\mathrm{Ru}^{\mathrm{IV}}(\mathrm{O})(\mathrm{tda})(\mathrm{py})_{2}\right], 4$, and $\left\{\left[\mathrm{Ru}^{\prime \prime}\left(\mathrm{OH}_{2}\right)\left(4-\mathrm{SO}_{3}-\mathrm{py}\right)_{2}\right]_{2}(\mu-\mathrm{Mebbp})\right\} ; 5^{-}$, complexes.

Under neutral and basic condition the seven coordinate complex $\left[\mathrm{Ru}^{\mathrm{IV}}(\mathrm{tda})(\mathrm{py})_{2}\right]^{2+}, \quad \mathbf{3}^{2+},\left(\mathrm{tda}^{2-} \quad\right.$ is $\quad\left[2,2^{\prime}: 6^{\prime}, 2^{\prime \prime}\right.$-terpyridine]-6,6"dicarboxylate), has recently been reported to undergo hydroxide substitution with concomitant proton loss to form $\left[\mathrm{Ru}^{\mathrm{IV}}(\mathrm{O})(\mathrm{tda})(\mathrm{py})_{2}\right], 4,\left(\mathrm{pK}_{\mathrm{a}}[\mathrm{Ru}(\mathrm{OH}) / \mathrm{Ru}(\mathrm{O})]=5.6\right)^{44}$ containing a pendant carboxylate that coexists with $3^{2+}$. Complex 4 has been shown to display a spectacular activity with regard to the catalytic oxidation of water with maximum turnover frequencies ranging from 8.000 to 50.000 cycles per second depending on the $\mathrm{pH}$ and thanks to the pendant group that acts as an intramolecular proton acceptor. From a mechanistic perspective, a WNA mechanism has been proposed based on DFT upon reaching $\left[\mathrm{Ru}^{\mathrm{V}}-\mathrm{O}\right]$ followed by $\mathrm{O}-\mathrm{O}$ bond formation via a water nucleophilic attack by a solvent water molecule in an analogous manner as described for $\mathbf{1}^{2+}$ in equations $1-2 .{ }^{44}$ 
Figure 1 shows a cyclic voltammogram of a mixture of $3.0 \mathrm{mM}$ $3^{2+}$ and $1.5 \mathrm{mM} 4$ at $\mathrm{pH}=7.0$ with a large electrocatalytic activity in the 1.3-1.6 V range that is associated with the generation of the corresponding $\left[\mathrm{Ru}^{\mathrm{V}}\right]$ complex whose $\mathrm{Ru}^{\mathrm{V}} / \mathrm{Ru}^{\mathrm{IV}}$ apparent potential occurs at $E^{o, a p}=1.43 \mathrm{~V}$. This apparent potential is obtained by Differential Pulse Voltammetry (DPV) although it has its intrinsic limitation, see supporting information for more details.

All the potentials in this work are measured vs. the mercury/mercurous sulfate (MSE, $\mathrm{K}_{2} \mathrm{SO}_{4}$ saturated at $25{ }^{\circ} \mathrm{C}$ ) reference electrode although are reported vs. NHE by adding $0.65 \mathrm{~V}$. We consider the peak current intensity of the wave associated with the background corrected (i.e., blank current subtracted) $\mathrm{Ru}^{\prime \prime \prime} / \mathrm{Ru}^{\prime \prime}$ couples as the "i $i_{p}$ " of the $\mathrm{Ru}^{\mathrm{V}} / \mathrm{Ru}^{\mathrm{IV}}$ couple. Here it is important to mention that FOWA considers that the electron transfer kinetics of the process coupled to the catalytic reaction is infinitely fast and thus assumes a reversible Nernstian behavior. Compelling evidence that advocates for Nernstian behavior in our complexes is suggested by the $59 \mathrm{mV}$ anodic-cathodic peak separation in the redox waves of $\mathbf{3}$ within the $50-500 \mathrm{mV} \cdot \mathrm{s}^{-1}$ range (see Figure S1) ${ }^{44,45,47}$ We thus assume Nernstian behavior in all the $1-5^{-}$complexes studied in this work. While this estimation of the standard potential of the redox couple is certainly not ideal, it is actually the only way to calculate it for the water oxidation catalysis. Therefore it constitutes an intrinsic limitation of FOWA applied to water oxidation catalysis.

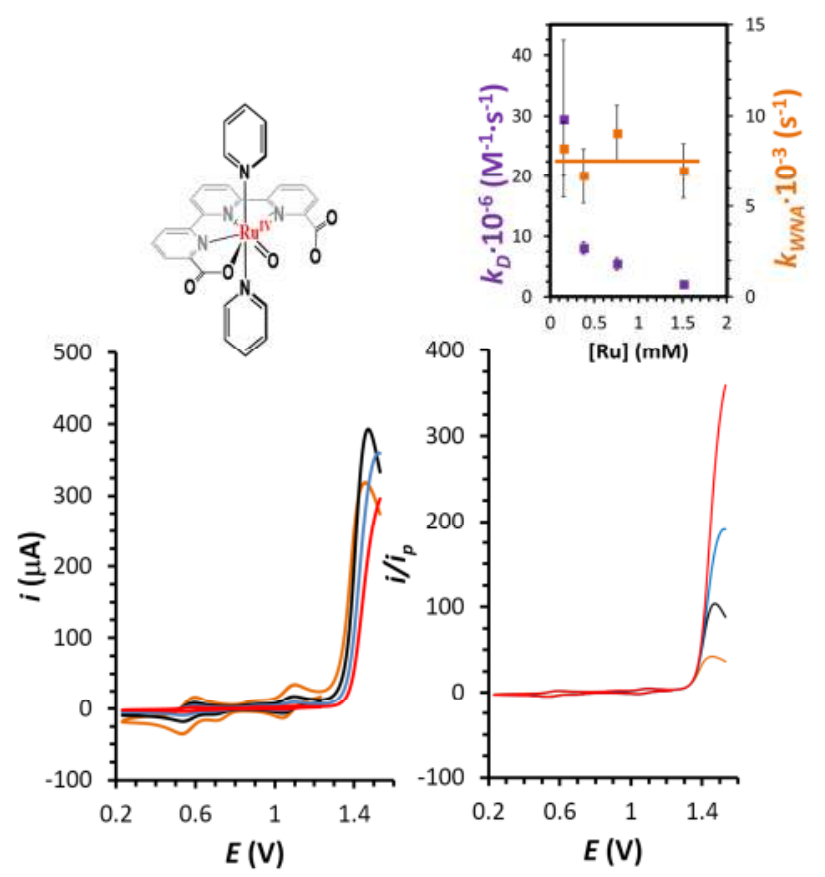

Figure 2: Left, $\mathrm{CV}$ of a $\mathbf{3} / \mathbf{4}$ mixture at $\mathrm{pH}=7$ at different concentrations (3.00 $\mathrm{mM} / 1.50 \mathrm{mM}$; orange solid line, $1.50 \mathrm{mM} / 0.75 \mathrm{mM}$; black solid line, 0.75 $\mathrm{mM} / 0.37 \mathrm{mM}$; blue solid line and $0.30 \mathrm{mM} / 0.15 \mathrm{mM}$; red solid line respectively). Right, $i_{p}$ normalized CVs. Inset, plot of calculated $k_{D}$ and $k_{W N A}$ vs. [4]. The standard deviation of each data point is represented with vertical lines. The solid orange line indicates the trend for the WNA mechanism.

For complex 4, the FOWA equations 8 and 9 in Table 1 were applied for the WNA and the I2M mechanisms respectively giving acceptable mathematical simulations in both cases as can be seen in the right hand side of Figure 1 where a plot of "i//ip" vs. "1/(1+e $\left.\left(\left(E^{0, a p}-E\right) \cdot(F / R T)\right)\right)$ " and vs. " $1 /\left(1+\mathrm{e}\left(\left(E^{o, a p}-E\right) \cdot(F / R T)\right)\right)^{3 / 2 \text { " is }}$ presented. ${ }^{56}$ To discern between the two mechanisms the FOWA methodology was carried out at different [Ru]. A set of CVs within the $0.15-1.50 \mathrm{mM}$ concentration range was carried out for 4 as shown in Figure 2 left, together with their $i_{p}$ normalized $\mathrm{CV}$ on the right hand side. The latter clearly shows that the slope ( $i / i_{p}$ " vs. E) at the foot of the wave zone for all the normalized CVs is identical and thus clearly points out to a WNA mechanism. Indeed the extraction of the apparent rate constants $k_{W N A}$ and $k_{D}$ values (FOWA equations 8 and 9 respectively) show that while for the former they are constant with a value of $(7.7 \pm 1.5) \cdot 10^{3} \mathrm{~s}^{-1}$, for the latter they decrease as the [Ru] increases. A plot of the $k$ values vs. [Ru] (see inset Figure 2) graphically shows this point and thus unambiguously confirms the WNA nature of the mechanism operating in this case. It is important to emphasize here that the dependence of the rate constant vs. catalysts concentration is the key tool to determine the reaction mechanism and on the other hand the consistency of the concentration dependence results obtained further reveals the virtue of the methodology used. The preference of this mechanism is readily explained by the intramolecular proton abstraction by the dangling carboxylate and by the steric hindrance that any potential mechanism based on a dimerization process will suffer for this particular complex. All the kinetic data obtained for this complex and all the other complexes described in this work are reported in Table 2.

Another interesting asset of the FOWA methodology is the fact that since the measurement is done at the foot of the wave, at the very beginning of the catalytic reaction, a number of undesired reactions or effects are either suppressed or minimized. ${ }^{38}$ In the case of Ru-tda complex 4, the water oxidation catalysis is so fast that significant changes of the local $\mathrm{pH}$ at the electrode surface are evidenced by an anodic shift of the $\mathrm{Ru}-\mathrm{OH}_{2}$ waves after catalysis. ${ }^{44}$ For this reason the value obtained with the classical Shain et al. methodology ${ }^{33}$ based on

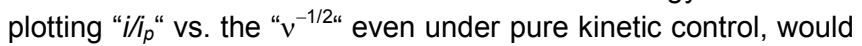
not give the correct apparent rate constant.

The same FOWA treatment was also applied for complex $\left\{\left[\mathrm{Ru}^{\prime \prime}\left(\mathrm{OH}_{2}\right)\left(4-\mathrm{SO}_{3}-\mathrm{py}\right)_{2}\right]_{2}(\mu-\mathrm{Mebbp})\right\}, 5^{-}$, (Mebpp is 3,5-di([2,2'bipyridin]-6-yl)-4-methylpyrazolate) that has been recently reported to undergo a WNA mechanism at $\mathrm{pH}=1.0$, based on $\mathrm{H}_{2}{ }^{18} \mathrm{O}$ labeling experiments. The FOWA at different [5] further confirm the proposed WNA nature of the mechanism as can be observed in the corresponding " $i / i_{p}$ " plots shown in Figure S5 in the SI. A constant value of TOF $\mathrm{MAX}=50 \pm 10 \mathrm{~s}^{-1}$ is obtained for this complex at different concentrations and all the related kinetic data is also presented in Table 2. 
2.4 The FOWA methodology applied to the $\left[R u^{I V}(O)(b d a)(p y)_{2}\right], 2$, complex.

As shown in the previous section the WNA mechanism operates in case of catalysts $\mathbf{4}$ and $\mathbf{5}^{-}$. We thus focused our endeavors on catalyst 2 , that had previously been shown to undergo an $12 \mathrm{M}$ type of mechanism at $\mathrm{pH}=1.0$ using $\mathrm{Ce}(\mathrm{IV})$ as a chemical oxidant. ${ }^{45}$ We carried out the analogous FOWA analysis at $\mathrm{pH}=$ 7.0 and 12.0, and the results are shown in the supporting information (Figure S8-S13), in Figure 3 and in Table 2. Figure 3 shows the cyclic voltammograms of complex 2 at $\mathrm{pH}=7.0$ at four different concentrations of $\mathrm{Ru}$ (in the $0.12-0.84 \mathrm{mM}$ range). As can be observed upon reaching the wave associated with the $\mathrm{Ru}^{\mathrm{V}} / \mathrm{Ru}^{\mathrm{IV}}$ couple a large electrocatalytic current emerges at approximately $1.1 \mathrm{~V}$, that increases with increasing concentration of the Ru catalyst. Figure 3 (right) shows the normalized " $i / i_{p}$ " voltammograms that now clearly show that the slope ( $i / i_{p}$ " vs. $\left.E\right)$ at the foot of the catalytic current increases with $[R u]$ and thus points towards an I2M type of mechanism. Indeed using equations 8 and 9 in Table 1 the apparent $k_{W N A}$ and $k_{D}$ were extracted and are plotted in the inset versus catalyst concentration. In sharp contrast with complex 4 the calculated $k_{D}=(160 \pm 40) \cdot 10^{3} \mathrm{M}^{-1} \cdot \mathrm{s}^{-1}$ is independent of the catalyst concentration whereas the calculated $k_{W N A}$ is dependent Thus, these experiments unambiguously show that the mechanism that operates at $\mathrm{pH}=7.0$ for Ru-bda complex $\mathbf{2}$ is the I2M. Finally, $k_{D}$ was used to estimate the TOF and TOF ${ }_{\text {MAX }}$ using equation 12 and 15 in Table 1 at $0.2 \mathrm{mM}$ concentration. This concentration value was used to compare the electrochemical TOFs at all $\mathrm{pHs}$ as well as with the ones obtained using CAN as sacrificial oxidant at $\mathrm{pH}=1.0 \mathrm{in}$ homogeneous phase. The same FOWA methodology was applied at $\mathrm{pH} 12$ for this catalyst obtaining very similar results (see SI Figure S11-S13 and Table 2), and confirming the I2M nature of the mechanism operating at this $\mathrm{pH}$. Very similar $k_{D}$ values were obtained at $\mathrm{pH}=7.0$ and 12.0 in a comparable range of concentrations confirming once again the independence of the rds on the concentration of $\mathrm{OH}^{-}$.
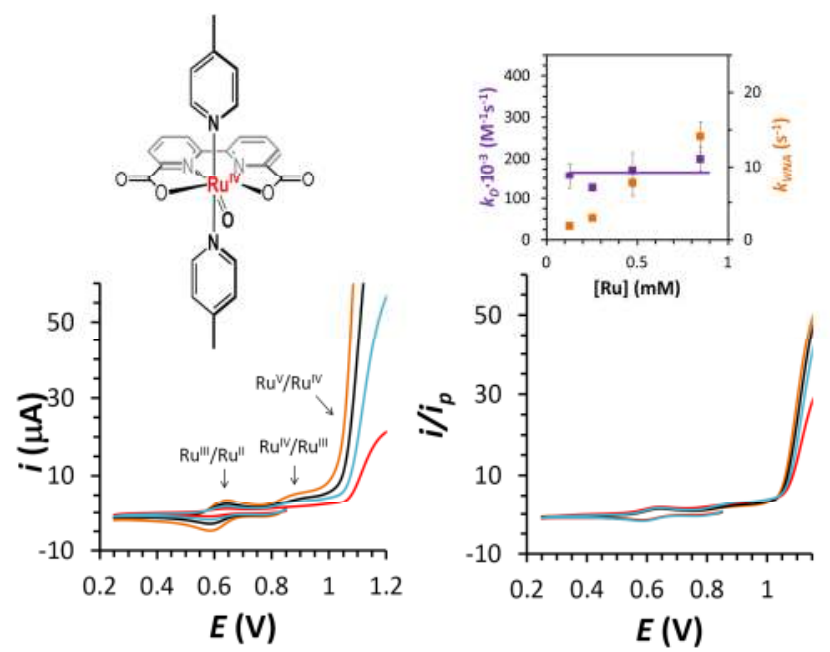

Figure 3. Left, CV of a 2 at $0.84 \mathrm{mM}$ (orange solid line), $0.47 \mathrm{mM}$ (black solid line), $0.25 \mathrm{mM}$ (blue solid line) and $0.12 \mathrm{mM}$ (red solid line) at $\mathrm{pH}=7.0$. The black solid arrows indicate the one-electron processes of $2{ }^{45}$ Right, $i_{p}$ normalized CVs. Inset, plot of calculated $k_{D}$ and $k_{W N A}$ vs. [2]. The standard deviation of each data point is represented with vertical lines. The solid purple line indicates the trend for the I2M mechanism.

At $\mathrm{pH}=1.0$ the solubility of the catalyst precursor, $\mathbf{2}$, is very low preventing a complete kinetic analysis using FOWA within a reasonable range of concentrations. For this reason we carried out the FOWA analysis for a single catalyst concentration, 0.2 $\mathrm{mM}$, and we run the $\mathrm{CV}$ at a scan rate of $10 \mathrm{mV} / \mathrm{s}$ (all the previous examples described were carried out at $100 \mathrm{mV} / \mathrm{s}$ ). This gave practically the same $k_{D}$ values as the ones obtained at higher $\mathrm{pH}$ (see SI Figure S19-S21 and Table 2) and thus confirms that for 2 the I2M mechanism operates over the $\mathrm{pH}$ range 1.0-12.0.

Finally, we proceeded to evaluate catalyst 2 under restricted translational mobility conditions by anchoring it on a glassy carbon electrode. Under these conditions complex 2 cannot undergo a bimolecular dimerization and thus needs to change the reaction mechanism for water oxidation catalysis. We anchored a related Ru-NO catalyst precursor, $\left\{\left[\mathrm{Ru}(\mathrm{NO})(\mathrm{bda})\left(\mathrm{PyPh}-\mathrm{N}_{2}{ }^{+}\right)_{2}\right]\left[\mathrm{PF}_{6}\right]_{3}\right\}, 6$, $\left(\mathrm{PyPh}-\mathrm{N}_{2}{ }^{+}\right.$is 4 -(pyridin-4$\mathrm{yl}$ )benzenediazonium), on the surface of the electrode following the reduction of its diazonium salt as has been recently described. ${ }^{46}$ In this way we generate a Ru-NO species at the surface of the electrode that is converted to GC-2 after one CV cycling in the range $0.2 \mathrm{~V}-1.5 \mathrm{~V}$ as described in our previous work and in the SI. ${ }^{46}$ The amount of GC-2 catalyst generated in this by this protocol ranges from 0.06 to $0.34 \mathrm{nmols} / \mathrm{cm}^{2}$, and nicely correlates with the initial concentration of 6 used (See Figure $\mathrm{S} 14$ in the $\mathrm{SI}$ ).

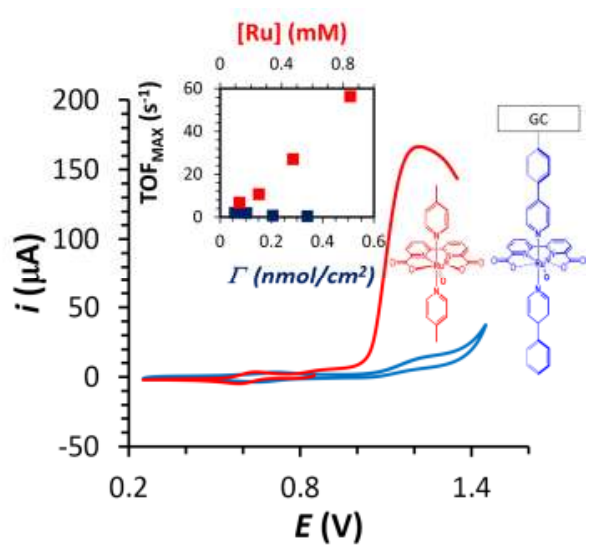

Figure 4. CV of $0.5 \mathrm{mM} 2$ that generates an $i_{\mathrm{p}}=1.9 \mu \mathrm{A}$ (red) and GC-2 with $\Gamma_{\text {cat }}^{\circ}=0.34 \mathrm{nmol} / \mathrm{cm}^{2}$ that generates $a i_{p}=2.6 \mu \mathrm{A}$ (blue) both at $\mathrm{pH}=7.0$. Inset,

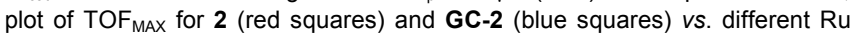
concentrations (red squares) and the Ru superficial concentrations (blue squares). The relative position of the two horizontal axis in the inset is set so that the $i_{\mathrm{p}}$ values for $\mathbf{2}$ and $\mathbf{G C}-\mathbf{2}$ are coincident (see figure S18 for the plot of TOF $_{\max } v s . i_{\mathrm{p}}$ values) 
Application of the FOWA methodology at different surface coverage $\left(0.06-0.39 \mathrm{nmol} / \mathrm{cm}^{2}\right.$ range, see SI Figure S15-S17) in this case using equation 10 in Table 1 gave a $k_{W N A}$ value of 1.9 $\mathrm{s}^{-1}$ (see inset Figure 4 and SI, Figure S17). The catalyst concentration independency with regard to the rate constant is a clear evidence for the mechanistic change, from I2M to WNA, due to the lack of translation mobility of the active species in GC-2. For higher surface coverages of 0.19 and $0.39 \mathrm{nmol} / \mathrm{cm}^{2}$ the apparent rate decreases to $0.6 \mathrm{~s}^{-1}$, a fact that might be attributed to surface effects associated with the electrode roughness. ${ }^{57}$ Further, the TOF MAX of GC-2 obtained by FOWA is similar to the TOF obtained in a previous work under heterogeneous conditions $\left(0.03-0.84 \mathrm{~s}^{-1}\right.$ within overpotentials in the 0.3-0.8 $\mathrm{V}$ window). They were calculated dividing the electrical charge associated to the $\mathrm{O}_{2}$ evolution $\left(\mathrm{Q}_{\mathrm{O}}\right)$ in a bulk electrolysis by the charge associated to the catalyst $\left(Q_{\mathrm{Ru}}\right)$ : TOF $=\mathrm{Q}_{\mathrm{O} 2} /\left(4 \cdot \mathrm{Q}_{\mathrm{Ru}}\right) .{ }^{46,58}$

In addition to the different mechanistic scenarios for $\mathbf{2}$ and GC-2, the physical meaning of $i_{p}$ in the voltammogram for dissolved species and $i_{p}$ in the voltammogram for the surface-confined systems is also different and therefore a direct comparison of apparent rate constants for $\mathbf{2}$ and $\mathbf{G C}-\mathbf{2}$ is meaningless. However it is very instructive to see the behavior of these two catalysts when their corresponding $i_{p}$ values are very similar. This can be observed in Figure 4 for [2] $=0.5 \mathrm{mM}$ and for GC-2 with a surface coverage of $0.34 \mathrm{nmol} / \mathrm{cm}^{2}$, both at $\mathrm{pH}=7.0$. Under these conditions the catalytic current density for $\mathbf{2}$ is more than one order of magnitude higher than for GC-2 at $E=1.2 \mathrm{~V}$ $\left(2.3 \mathrm{~mA} / \mathrm{cm}^{2}\right.$ vs. $\left.0.2 \mathrm{~mA} / \mathrm{cm}^{2}\right)$.

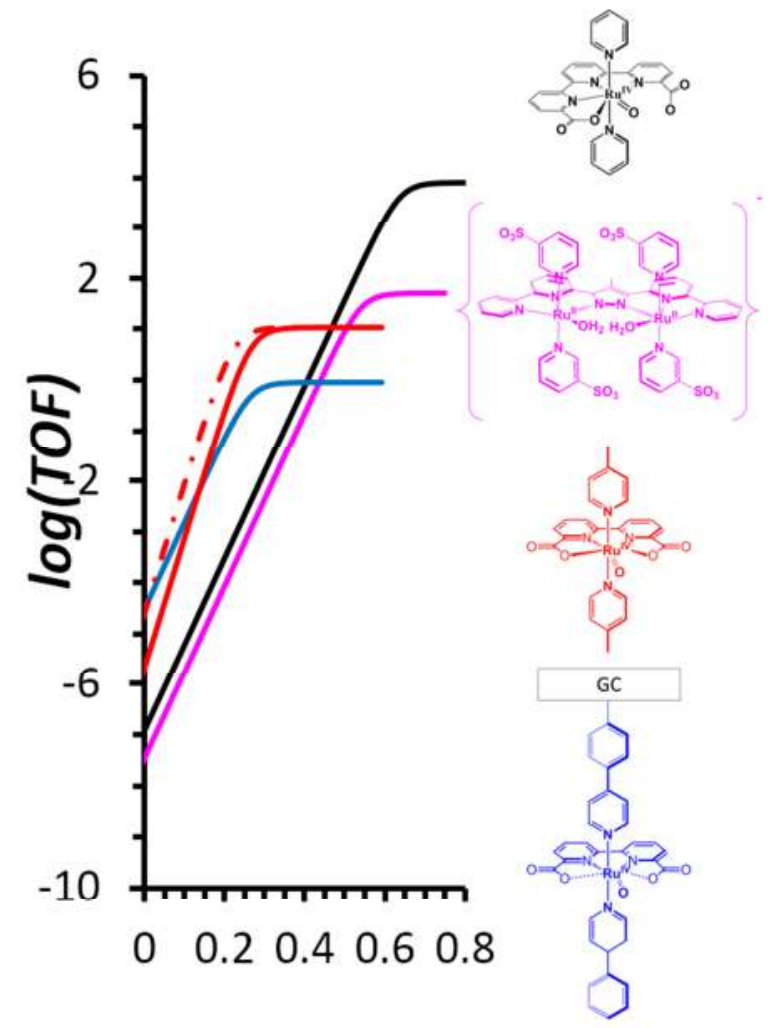

$\eta(\mathrm{V})$

Figure 5: Catalytic Tafel plot of $\mathbf{5}^{-}$and $\mathbf{2}$ at $\mathrm{pH}=1.0$ (pink solid line and red dashed line respectively) and 2,4 and $\mathbf{G C}-2$ at $\mathrm{pH}=7.0$ (red, black and blue solid lines respectively). The green dashed line represents the potential of $E^{\circ}$ $\left(\mathrm{Ce}^{\mathrm{IV}} / \mathrm{Ce} \mathrm{e}^{\mathrm{III}}\right)$ at $\mathrm{pH}=1.0$. For catalyst 2 , a concentration of $0.2 \mathrm{mM}$ was used for the plot.

\subsection{Catalytic Tafel plots based on FOWA equations.}

The catalytic Tafel plots used in this work are different from the commonly used "electrochemical Tafel plots". The electrochemical Tafel plots define a relationship between the current density and the overpotential with respect to the equilibrium potential. ${ }^{59,60}$ On the other hand catalytic Tafel plots establish a relationship between the Turn Over Frequency of the catalyst and the applied potential with respect to the standard potential of the reaction. ${ }^{35,38}$

Catalytic Tafel graphs were drawn by plotting TOF as a function of overpotential $(\eta)$ following equations 11,12 and 13 in Table 1 for the WNA, I2M and hetero-WNA mechanisms respectively. ${ }^{35}$ Figure 5 illustrates the catalytic Tafel plots for the complexes discussed in this work, allowing an easy and quick comparison among them. There are three key features that define the shape of the Tafel plot and thus reflects the activity and nature of the catalyst: a) the TOF curve reaches a Plateau and that is described by equations 14 , 15 and 16 in Table 1 for the WNA, I2M and hetero-WNA 
mechanisms respectively, b) the lowest value of potential where TOF $=$ TOF $_{\text {MAX }}$ and $c$ ) the slope that defines the relationship between TOF and overpotential which is a distinctive feature of each mechanism.

\section{Discussion}

The equations reported in this work that are summarized in Table 1 provide a valuable tool for the integral treatment of molecular water oxidation electrocatalysis. The data analysis allows to progress one step forward by unravelling the mechanisms operating for a given catalyst and in addition the detailed kinetic information also allows comparing catalysts under similar conditions. The latter is very important since so far the kinetic values reported were obtained in drastically different conditions and therefore difficult to compare. Furthermore, the variation of the apparent rate constant as a function of overpotential graphically shown by the catalytic Tafel plots, offer a comprehensive view of the catalyst performance as a function of the applied potential. Benchmarking conditions had been recently proposed to compare WOCs based on solid metal oxides. $^{20,21}$ On the other hand catalytic Tafel plots have been used to benchmark molecular proton reduction catalysts. ${ }^{61}$. ${ }^{62}$ Here for the first time a comparison under the same conditions over a large span of overpotentials is carried out based on catalytic Tafel plots for molecular water oxidation catalysts.

Figure 5 shows Tafel plots for complexes 2, 4, 5' and GC-2 and a number of conclusions can be drawn from the careful examination of this graph. At high overpotentials $(\eta>0.6 \mathrm{~V})$

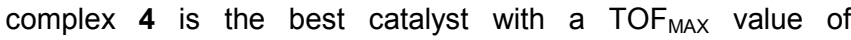
$(7.7 \pm 1.5) \cdot 10^{3} \mathrm{~s}^{-1}$ that is almost two orders of magnitude higher than that of the naturally occurring reaction in the OEC of Photosystem II and three orders of magnitude higher than that of complex 2, which is one of the best catalysts described so far. Furthermore the WNA mechanism obtained here is consistent with the molecular structure of the catalyst as the dangling carboxylate at the $\left[\mathrm{Ru}^{\mathrm{V}}=\mathrm{O}\right]$ oxidation state favors the intramolecular proton transfer of an approaching water molecule for the critical O-O bond formation step, and thus favors the WNA mechanism. For these reasons catalyst $\mathbf{4}$ would be an ideal catalyst to anchor at the surface of a semiconductor that generated light induced high energy holes. For instance semiconductors such as $\mathrm{BiVO}_{4}$ or $\mathrm{WO}_{3}$ that have very oxidizing valence bands of approximately 2.5 and $3 \mathrm{~V}$ respectively, ${ }^{6}$ and thus are ideal to be integrated in such a photoanode for a water splitting electrochemical cells..$^{63,64}$

On the other hand, at high overpotentials catalyst 4 has a TOF $_{\text {MAX }}$ that is $\mathbf{2}$ orders of magnitude higher than the dinucleating Ru-Mebbp complex 5: However at lower overpotentials the TOF of the two complexes differ in less than an order of magnitude and thus would be equally valuable for potential water splitting applications. In addition, the catalytic experiments are carried out at $\mathrm{pH}=7.0$ for 4 and at $\mathrm{pH}=1.0$ for 5: Therefore this leaves us with a couple of excellent WNA type of catalyst at low overpotentials within the $\mathrm{pH}$ range 1-7.

At $\eta=0.45 \mathrm{~V}$ the plots of catalyst 2 and 4 cross and thus indicates that under this conditions they have identical behavior. Please note that while for the WNA cases the plot is independent of the catalyst concentration for the I2M it depends on the initial catalysts concentration. Here we use [2] $=0.2 \mathrm{mM}$ which is close to saturation but is a value reasonably achievable for other molecular WOCs. At lower overpotentials, 2 clearly outperforms 4 in homogeneous phase and is the best catalyst studied in this work. In addition higher TOFs can be obtained for complexes analogous to 2 , by fine tuning the axial ligand reaching TOFs up to $1000 \mathrm{~s}^{-1}$ at $\mathrm{pH}=1.0$ with a huge excess of $\mathrm{Ce}(\mathrm{IV})$ as chemical oxidant. ${ }^{65,66}$

It is also interesting to stress the mechanistic $\mathrm{O}-\mathrm{O}$ bond formation change of catalyst 2 in homogenous phase and anchored on the GC electrode, GC-2, from I2M to WNA respectively due to the restricted translation mobility of the latter. This mechanistic change has been proposed earlier but has been demonstrated here for the first time based on the FOWA analysis with different catalyst surface concentrations for GC-2 and different concentrations for 2 . The absence of a bimolecular path at the anchored GC-2 catalyst involves access to a path that is obviously higher in energy and produces a decrease of the activity that in addition enables deactivation pathways, ultimately leading to the formation of $\mathrm{RuO}_{2}$ dispersed at the surface of the electrode as has been shown recently. ${ }^{46}$

Finally, using $\mathrm{Ce}(\mathrm{IV})$ at $\mathrm{pH}=1.0$ an apparent rate constant of $0.07 \mathrm{~s}^{-1}$ is obtained for $5^{-}$which implies an overpotential of 0.38 $\mathrm{V}$ according to equation 11 and assuming that the TOF for $5^{-}$in homogeneous phase depends on electron transfer. ${ }^{47}$ This would be associated with a $E^{\circ}$ for the $\mathrm{Ce}(\mathrm{IV}) / \mathrm{Ce}(\mathrm{III})$ couple of $1.55 \mathrm{~V}$ which falls within the 1.46-1.63 $\mathrm{V}$ range reported. ${ }^{67,68,69,70,71}$ For complex 2 the TOF obtained at $\mathrm{pH}=1.0$ with $\mathrm{Ce}(\mathrm{IV})$ is $30 \mathrm{~s}^{-1,45}$ which compares well with the TOF $\mathrm{MAX}=11 \mathrm{~s}^{-1}$ value obtained by FOWA assuming also $\eta=0.38 \mathrm{~V}$ at [2] $=0.2 \mathrm{mM}$. However a direct comparison can't be made since in homogeneous phase at this concentration range the rds depends on both the $k_{D}$ and $k_{\mathrm{O} 2}$, but is independent on $\mathrm{Ce}(\mathrm{IV})$.

It is also worth realizing that TOF values are highly dependent on the $\eta$ and thus the goodness of a catalyst can't be judged with a single chemical oxidant. For instance in the case of catalysts 2 and $\mathbf{5}^{-}$, the former is better at low $\eta$ and the latter at high $\eta$.

\section{Conclusions}

In conclusion, we have adapted the electrochemical methodology of the foot of the wave analysis (FOWA) to electrochemical water oxidation. That allows calculating catalytic water oxidation apparent rate constants in a very simple and 
reliable manner. These equations also allow elucidating the first or second order catalyst dependence on the electrocatalytic peak current at the foot of the wave that is directly related to the $\mathrm{O}-\mathrm{O}$ bond formation step in the case where this step is the rds. In these cases this allows distinguishing between WNA and I2M type of mechanisms. Finally, the catalytic Tafel plots are used for easily and graphically comparing WOCs under identical conditions and thus are valuable for choosing the right catalyst for a specific application.

\section{Acknowledgements}

R.M. thanks "La Caixa" foundation for a PhD grant. A.L. thanks MINECO (CTQ-2013-49075-R, SEV-2013-0319; CTQ-201452974-REDC; ENE2014-52280-REDT) and "La Caixa" foundation for financial support. X.S. thanks MINECO/FEDER for financial support (CTQ2015-64261-R). F.M. thanks the DFG (Me 1313/9-1 in the ERA Chemistry framework and SFB 1073, project C01) for financial support, and S.N. thanks the international $\mathrm{PhD}$ program CaSuS (Catalysis for Sustainable Synthesis) for a PhD fellowship. FEDER and European COST actions, CM1202 and CM1205 are also gratefully acknowledged.

Keywords: water oxidation $\cdot$ water splitting $\bullet$ reaction mechanisms $\bullet$ catalysis electrocatalysis $\bullet$ foot of the wave analysis $\cdot$ benchmarking

\section{References}

${ }^{1}$ N. S. Lewis and D. G. Nocera, Proc. Natl. Acad. Sci. USA, 2006, 103, 1572915735.

${ }^{2}$ C.-J. Zhong, J. Luo, P. N. Njoki, D. Mott, B. Wanjala, R. Loukrakpam, S. Lim, L. Wang, B. Fang and Z. Xu, Energy Environ. Sci. 2008, 1, 454-466.

${ }^{3}$ N. S. Lewis, Science 2016, 351, 353.

${ }^{4}$ J. Marshall, Nature, 2014, 510, 22-24.

${ }^{5}$ F. Rappaport, M. Guergova-Kuras, P. J. Nixon, B. A. Diner and J. Lavergne, Biochemistry, 2002, 41, 8518-8527.

${ }^{6}$ J. R. McKone, N. S. Lewis and H. B. Gray, Chem. Mater. 2014, 26, 407-414.

7 J. Luo, J.-H. Im, M. T. Mayer, M. Schreier, M. K. Nazeeruddin, N.-G. Park, S. D. Tilley, H. J. Fan and M. Grätzel, Science, 2014, 345, 1593-1596.

${ }^{8}$ M. Suga, F. Akita, K. Hirata, G. Ueno, H. Murakami, Y. Nakajima, T. Shimizu, K. Yamashita, M. Yamamoto, H. Ago and J.-R. Shen, Nature, 2015 517, 99-103

9 J. J. Concepcion, R. L. House, J. M. Papanikolas and T. J. Meyer, Proc. Natl. Acad. Sci. USA, 2012, 109, 15560-15564.

${ }^{10}$ B. Kumar, M. Llorente, J. Froehlich, T. Dang, A. Sathrum and C. P. Kubiak, Annu. Rev. Phys. Chem. 2012, 63, 541-569.

${ }^{11} \mathrm{~F}$.-F. Li and S. Licht, Inorg. Chem. 2014, 53, 10042-10044.

${ }^{12}$ Molecular Water Oxidation Catalysis: A Key Topic for New Sustainable Energy Conversion Schemes. 2014 Edited by A. Llobet. John Wiley and Sons Ltd.

13 L. Francas, X. Sala, E. Escudero-Adan, J. Benet-Buchholz, L. Escriche and A. Llobet, Inorg. Chem. 2011, 50, 2271-2781.

14 D. Hong, S. Mandal, Y. Yamada, Y.-M. Lee, W. Nam, A. Llobet and S. Fukuzumi, Inorg. Chem. 2013, 52, 9522-9531.

15 A. Singh and L. Spiccia, Coord. Chem. Rev. 2013, 257, 2607-2622.
${ }^{16}$ A. Coehn, M. Gläser, Z. Anorg. Chem. 1902, 33, 9-24.

${ }^{17}$ A.C.C. Tseung and S. Jasem, Electrochim. Acta, 1977, 22, 31-34

${ }^{18}$ Y. Matsumoto, E. Sato, Electrochim. Acta, 1979, 24, 421-423.

${ }^{19}$ A. Harriman, I. J. Pickering, J. M. Thomas and P. A. Christensen, J. Chem. Soc. Faraday Trans. 1988, 84, 2795-2806.

${ }^{20}$ C. C. L. McCrory, S. Jung, J. C. Peters and T. F. Jaramillo, J. Am. Chem. Soc. 2013, 135, 16977-16987.

${ }^{21}$ C. C. L. McCrory, S. Jung, I. M. Ferrer, S. M. Chatman, J. C. Peters and T. F. Jaramillo, J. Am. Chem. Soc. 2015, 137, 4347-4357.

${ }^{22}$ S. Jung, C. C. L. McCrory, I. M. Ferrer, J. C. Peters, T. F. Jaramillo, J. Mater. Chem. A, 2016, 4, 3068-3076.

${ }^{23}$ C. Sens, I. Romero, M. Rodriguez, A. Llobet, T. Parella and J. BenetBuchholz, J. Am. Chem. Soc, 2004, 126, 7798-7799.

${ }^{24}$ R. Zong and R. P. Thummel, J. Am. Chem. Soc. 2005, 127, 12802-12803.

${ }^{25}$ J. J. Concepcion, J. W. Jurss, J. L. Templeton and T. J. Meyer, J. Am. Chem. Soc. 2008, 130, 16462-16463.

${ }^{26}$ H. Lv, J. Song, Y. V. Geletii, J. W. Vickers, J. M. Sumliner, D. G. Musaev, P. Kögerler, P. F. Zhuk, J. Bacsa, G. Zhu and C. L. Hill, J. Am. Chem. Soc. 2014, 136, 9268-9271.

${ }^{27}$ L. Duan, A. Fischer, Y. Xu and L. Sun, J. Am. Chem. Soc. 2009, 131, 10397-10399.

${ }^{28}$ P. Garrido-Barros, I. Funes-Ardoiz, S. Drouet, J. Benet-Buchholz, F. Maseras and A. Llobet, J. Am. Chem. Soc. 2015, 137, 6758-6761.

${ }^{29}$ S. M. Barnett, K. I. Goldberg and J. M. Mayer, Nat. Chem. 2012, 4, 498-502.

${ }^{30}$ D. E. Polyansky, J. T. Muckerman, J. Rochford, R. Zong, R. P. Thummel and E. Fujita, J. Am. Chem. Soc. 2011, 133, 14649-14665.

${ }^{31}$ E. S. Rountree, B. D. McCarthy, T. T. Eisenhart and J. L. Dempsey, Inorg. Chem. 2014, 53, 9983-10002.

${ }^{32}$ N. Song, J. J. Concepcion, R. A. Binstead, J. A. Rudd, A. K. Vannucci, C. J. Dares, M. K. Coggins and T. J. Meyer, Proc. Natl. Acad. Sci. USA, 2015, 112, 4935-4940.

${ }^{33}$ R. S. Nicholson, I. Shain, Anal. Chem. 1964, 36, 706-723.

${ }^{34}$ Electrochemical Methods, Fundamentals and Applications. Allen J. Bard and Larry R. Faulkner, John. Wiley \& Sons, Inc. $2^{\text {nd }}$ Ed, New York, NY, 2001. See Chapter 12, section 3.5.

${ }^{35}$ C. Costentin, S. Drouet, M. Robert and J.-M. Savéant, J. Am. Chem. Soc. 2012, 134, 11235-11242.

${ }^{36}$ C. Costentin, S. Drouet, M. Robert and J.-M. Savéant, Science, 2012, 338 90-94.

${ }^{37}$ V. Artero and J.-M. Saveant, Energy Environ. Sci. 2014, 7, 3808-3814.

${ }^{38}$ C. Costentin and J.-M. Savéant, ChemElectroChem, 2014, 1, 1226-1236.

39 C. Costentin, H. Dridi, J.-M. Savéant, J. Am. Chem. Soc. 2014, 136, $13727-$ 13734.

${ }^{40}$ C. Costentin, G. Passard and J.-M. Savéant, J. Am. Chem. Soc. 2015, 137, 5461-5467.

41 Elements of Molecular and Biomolecular Electrochemistry: An Electrochemical Approach to Electron Transfer Chemistry, J.-M. Savéant, John. John Wiley \& Sons, Inc. Hoboken, New Jersey, 2006.

${ }^{42}$ D. J. Wasylenko, C. Rodríguez, M. L. Pegis and J. M. Mayer, J. Am. Chem. Soc. 2014, 136, 12544-12547.

${ }^{43}$ L. Vigara, M. Z. Ertem, N. Planas, F. Bozoglian, N. Leidel, H. Dau, M. Haumann, L. Gagliardi, C. J. Cramer and A. Llobet, Chem. Sci. 2012, 3 , 2576-2586.

${ }^{44}$ R. Matheu, M. Z. Ertem, J. Benet-Buchholz, E. Coronado, V. S. Batista, X. Sala and A. Llobet, J. Am. Chem. Soc. 2015, 137, 10786-10795.

${ }^{45}$ L. Duan, F. Bozoglian, S. Mandal, B. Stewart, T. Privalov, A. Llobet and L. Sun, Nat. Chem. 2012, 4, 418-423.

${ }^{46}$ R. Matheu, L. Francàs, P. Chernev, M. Z. Ertem, V. Batista, M. Haumann, X. Sala and A. Llobet, ACS Catal. 2015, 5, 3422-3429.

${ }^{47}$ S. Neudeck, S. Maji, I. Lopez, S. Meyer, F. Meyer and A. Llobet, J. Am. Chem. Soc. 2014, 136, 24-27.

${ }^{48}$ X. Sala, S. Maji, R. Bofill, J. Garcia-Anton, L. Escriche and A. Llobet, Acc. Chem. Res. 2014, 47, 504-516. 
${ }^{49}$ D. J. Wasylenko, C. Ganesamoorthy, M. A. Henderson, B. D. Koivisto, H. D. Osthoff and C. P. Berlinguette, J. Am. Chem. Soc. 2010, 132, 1609416106.

${ }^{50}$ S. Maji, L. Vigara, F. Cottone, F. Bozoglian, J. Benet-Buchholz and A. Llobet, Angew. Chem. Int. Ed. 2012, 51, 5967-5970.

51 S. Roeser, P. Farras, F. Bozoglian,M. Martinez-Belmonte, J. BenetBuchholz and A. Llobet, Chem.Sus. Chem. 2011, 4, 197-197.

${ }^{52}$ S. Romain, F. Bozoglian, X. Sala, A. Llobet, J. Am. Chem. Soc. 2009, 131, 2768-2769.

${ }^{53}$ Neudeck, S.; Maji, S.; Lopez, I.; Dechert, S.; Benet-Buchholz, J.; Llobet, A.; Meyer, F. Inorg. Chem. 2016, 55, 2508-2521.

${ }^{54}$ Berardi, S.; Francas, L.; Neudeck, S.; Maji, S.; Benet-Buchholz, J.; Meyer, F.; Llobet, A. ChemSusChem 2015, 8, 3688-3696.

${ }^{55}$ See page 23 in the supporting information of C. Costentin and J. M. Saveant, Chem.ElectroChem, 2014, 1, 1226-1236.

56 For the mathematical simulations between 50 and 100 points are systematically used with $\mathrm{R}$ factors higher than 0.97 .

${ }^{57}$ D. Belanger and J. Pinson, Chem. Soc. Rev. 2011, 40, 3995-4048.

${ }^{58}$ F. Li, B. Zhang, X. Li, Y. Jiang, L. Chen, Y. Li and L. Sun, Angew. Chem. Int. Ed. 2011, 123, 12484-12487.

${ }^{59}$ The Tafel equation celebrated the 100th anniversary in 2005. See Ref. 59
${ }^{60}$ J. Tafel, K. Schmitz, K. Naremann and B. Emmert: Z. Phys. Chem. 1905, 50, 713-752.

${ }^{61}$ C. Costentin, G. Passard, J.-M. Savéant, J. Am. Chem. Soc. 2015, 137, 5461-5467.

${ }^{62}$ V. Artero, J.-M. Saveant, Energy Environ. Sci. 2014, 7, 3808-3814.

${ }^{63}$ N. Guijarro, M. S. Prevot and K. Sivula, Phys. Chem. Chem. Phys. 2015, 17, 15655-15674.

${ }^{64}$ Y. Ma, S. R. Pendlebury, A. Reynal, F. Le Formal and J. R. Durrant, Chem. Sci. 2014, 5, 2964-2973.

${ }^{65}$ C. J. Richmond, R. Matheu, A. Poater, L. Falivene, J. Benet-Buchholz, X. Sala, L. Cavallo and A. Llobet, Chem. Eur. J. 2014, 20, 17282-17286.

${ }^{66}$ L. Wang, L. Duan, Y. Wang, M. S. G. Ahlquist and L. Sun, Chem. Commun. 2014, 50, 12947-12950.

${ }^{67}$ The standard potential of the Ce(IV/III) couple is highly sensitive to $\mathrm{pH}$, ionic strength, anion nature etc. See references: 59-62.

${ }^{68}$ V. Nair, A. Deepthi, Chem. Rev. 2007, 107, 1862-1891.

${ }^{69}$ S. A. Hayes, P. Yu, T. J. O'Keefe, M. J. O'Keefe and J. O. Stoffer J. Electrochem. Soc. 2002, 149, 623-630.

${ }^{70}$ P. Yu, T. J. O'Keefe, J. Electrochem. Soc. 2006, 153, 80-85.

${ }^{71}$ T. N. Bondareva, A. G. Stromberg, Zh. Obsh. Khim. 1955, 25, 639-642. 


\section{FULL PAPER}

Text for Table of Contents

Roc Matheu, Sven Neudeck, Franc Meyer, Xavier Sala* and Antoni Llobet ${ }^{\star}$

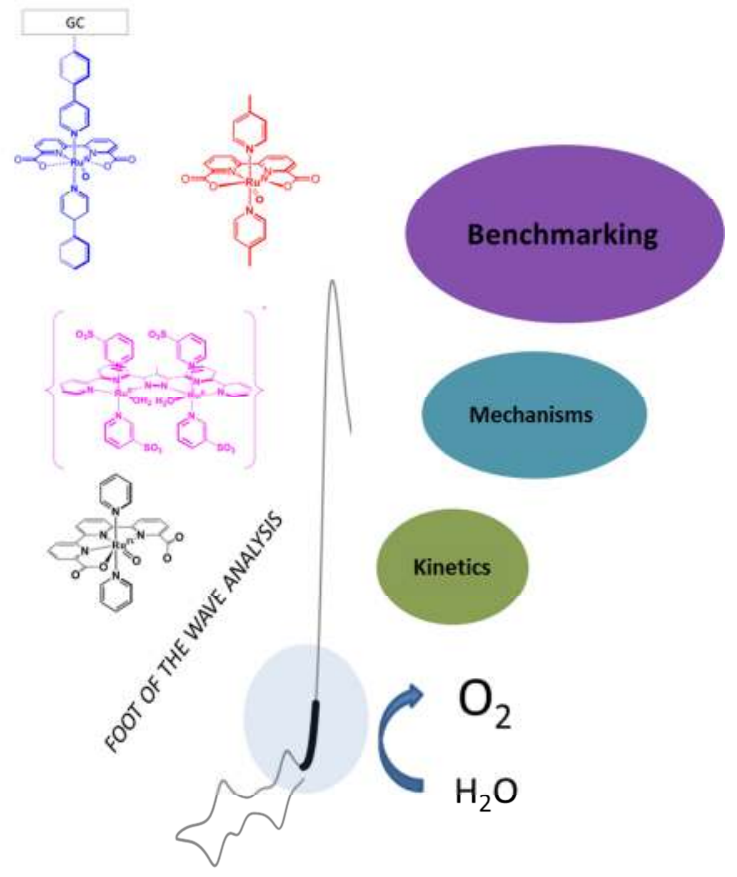

Page No. - Page No.

Title 